\title{
The Control of Water Supplies
}

$\mathrm{T}$ HE first report of the Central Advisory Water Committee, just issued from the Ministry of Health (H.M. Stationery Office, $6 d$. net), summarizes the conclusions arrived at by the Committee on a number of suggestions submitted to it for new legisla. tion to facilitate the conservation and supply of water and the co-ordination of water interests. The most urgent of these questions, in the Committee's opinion, were proposals for $(a)$ the control and conservation of needed underground water resources and the protection of underground water from pollution; $(b)$ the planning of water resources and supplies; and (c) the modernization of the existing law relating to the supply of water by local authorities and water companies.

With regard to the first matter, the approved findings of a special underground water sub-committee are given in which it is recommended that control should be exercised only in defined areas in which the conservation of underground water is shown, after investigation, including public inquiry, to be necessary in the public interest, with the further recommendation that the Minister of Health should be empowered, either on his own initiative, or on the application of any interested regional advisory water committee or person, and after consultation with the Central Advisory Water Committee, to make orders defining areas in which control of the abstraction of underground water is necessary in the public interest. These, with certain other recommendations relating to waste and pollution of supplies, it is noted, will entail substantial amendment of the existing law, under which owners have the unrestricted right to abstract water from under their land, or to allow underground resources which they have tapped to run to waste ; they affect also, to some extent, the powers of owners to dispose of waste matters which may cause pollution. The Committee is satisfied, however, as to the necessity and value of the suggested provisions.

The second of the questions under consideration, namely, the planning of water resources and supplies, forms the subject of another special report by a sub- committee, in which it is pointed out that the regional planning of public water supplies by joint committees of water undertakers is of comparatively recent origin. There are now nine regional committees in existence, comprising areas with a total population of some fifteen millions. Although the central committee is satisfied as to the need for regional planning by regional committees, it considers the existing pro. cedure should be amended and that in place of volun. tary assistance in their researches, the regional committees should be empowered by statute to make precepts on constituent authorities for their expenses and to obtain necessary information of consumption and resources. The Minister of Health should, in the Committee's opinion, be empowered to require all persons abstracting water to furnish returns of any water abstracted and not returned to the stream from which it was taken, an exception being made in favour of private individuals who abstract water for their own domestic use. With certain reservations in regard to details, these returns should be made public to the extent of affording information in the aggregate of the quantity of water abstracted in suitable areas.

The reconstitution of the regional committees is advocated in order to obtain greater efficiency, a limit of 10 members in each being considered desirable, inclusive of an independent chairman. The lack of contact between water undertakers and other interests is met by the recommendation that it should be obligatory for the committees to consult all interested bodies, including catchment boards, fishery boards, harbour and navigation authorities and industrial users, before definite proposals are formulated in which the interests of these bodies are likely to be affected. Other recommendations are made for increasing the powers of the Minister of Health in regard to the formation or alteration of joint boards and the amalgamation and acquisition of water undertakings. As regards the modernization of the law relating to water supply, it is stated a consolidation bill is in course of being drafted for submission to the Minister of Health.

B. C.

\section{The Museums Association}

\section{Annual Conference at Belfast}

$\mathrm{T}$ HE forty-ninth Annual Conference of the Museums Association was held in Belfast in the week commencing July 4, and was attended by representatives of museums of all parts of Great Britain and by a number of delegates from overseas. The president, Dr. R. E. Mortimer Wheeler, announced that Her Majesty Queen Mary had graciously consented to become the patroness of the Association.

In his presidential address, Dr. Wheeler dealt with a number of current museum problems, and referred especially to the need for folk parks in England, and for the preservation, either there or elsewhere, of historic horse-drawn vehicles which have now become obsolete.

A large part of Dr. Wheeler's address was concerned with air raid precautions in museums and art galleries. The Museums Association has held a meeting on this subject, and has approached the Standing Commission on National Museums for advice. Museum buildings may be reinforced, deep basements or country house storage may be provided for objects of primary importance, and a plan prepared for immediate action in case of emergency. Any person, Dr. Wheeler said, who is directly or 